\title{
Massive transfusion protocols: current best practice
}

This article was published in the following Dove Press journal:

International Journal of Clinical Transfusion Medicine

10 March 2016

Number of times this article has been viewed

\author{
Yen-Michael S Hsu' \\ Thorsten Haas ${ }^{2}$ \\ Melissa M Cushing' \\ 'Department of Pathology and \\ Laboratory Medicine, Weill Cornell \\ Medical College, New York, NY, USA; \\ ${ }^{2}$ Department of Anesthesia, University \\ Children's Hospital Zurich, Zurich, \\ Switzerland
}

Correspondence: Yen-Michael S Hsu Department of Pathology and Laboratory Medicine, Weill Cornell Medical College, 525 East 68th Street, Box 25I,

New York, NY, USA

$\mathrm{Tel}+\mathrm{I} 2127462212$

Fax + I 2127468435

Email ysh900I@med.cornell.edu

\begin{abstract}
Massive transfusion protocols (MTPs) are established to provide rapid blood replacement in a setting of severe hemorrhage. Early optimal blood transfusion is essential to sustain organ perfusion and oxygenation. There are many variables to consider when establishing an MTP, and studies have prospectively evaluated different scenarios and patient populations to establish the best practices to attain improved patient outcomes. The establishment and utilization of an optimal MTP is challenging given the ever-changing patient status during resuscitation efforts. Much of the MTP literature comes from the trauma population, due to the fact that massive hemorrhage is the leading cause of preventable trauma-related death. As we come to further understand the positive and negative clinical impacts of transfusion-related factors, massive transfusion practice can be further refined. This article will first discuss specific MTPs targeting different patient populations and current relevant international guidelines. Then, we will examine a wide selection of therapeutic products to support MTPs, including newly available products and the most suitable of the traditional products. Lastly, we will discuss the best design for an MTP, including ratio-based MTPs and MTPs based on the use of point-ofcare coagulation diagnostic tools.
\end{abstract}

Keywords: hemorrhage, MTP, antifibrinolytics, coagulopathy, trauma, ratio, logistics, guidelines, hemostatic

\section{Introduction and definition of massive transfusion}

The importance of prompt blood replacement in the setting of uncontrolled hemorrhage is well established and intuitively practiced to resuscitate exsanguinating patients. During combat, trauma-associated hemorrhage due to penetrating or blunt injury is often supported by transfusion of whole blood (WB) collected directly from other soldiers. This historical military practice has evolved into a bleeding management strategy for hemorrhagic shock known as damage control resuscitation in the civilian setting. While the military massive transfusion (MT) practices have been refined to improve outcomes over time, the difference in the types of traumatic or non-traumatic injuries, patient health conditions, availability of blood products, and provider-related factors must be considered before applying the same MT practices to a civilian setting. ${ }^{1,2}$ The objective of this article is to provide guidance on how to optimize massive transfusion protocols (MTPs) in the trauma and non-trauma settings. We will define MT and discuss different types of MTPs, review expert guidelines available for MTPs, provide guidance for the use of therapeutic hemostatic products, discuss the relevance of point-of-care (POC) coagulation testing and blood product ratios during an MTP, and finally conclude with practical logistical and safety considerations maximize an MTP. 


\section{Definition of MT}

MT is defined when either 1) total blood volume is replaced within 24 hours, 2) $50 \%$ of total blood volume is replaced within 3 hours, or 3) rapid bleeding rate is documented or observed. Rapid bleeding rate in adults can be defined as more than 4 units of red blood cells (RBCs) transfused within 4 hours with active major bleeding or more than $150 \mathrm{~mL} /$ minute of blood loss. The definition of MT in children is slightly different from the definition in adults but is beyond the scope of this review. ${ }^{3,4}$

\section{Types of MTPs}

\section{Trauma MTPs}

At the onset of severe traumatic bleeding, aggressive fluid replacement and rapid mechanical/surgical bleeding control can often mitigate the extent of tissue injury, inflammation, and hypoperfusion. However, untimely or incomplete control of massive bleeding can lead to systemic consumptive coagulopathy with hemodilution and endothelial damage ${ }^{5,6}$ If the systemic damage remains uncorrected, concurrent trauma-associated hypothermia and acidosis can further exacerbate coagulopathy and lead to irreversible multiorgan failure (MOF). In addition, older age ( $>55$ years old), high injury severity score (ISS $>15$ ), high base deficit $(>8 \mathrm{mEq} / \mathrm{L})$, high lactate $(>2.5 \mathrm{mmol} / \mathrm{L})$, and blood transfusion have been observed as independent risk factors for MOF in both retrospective and prospective studies. ${ }^{7,8}$ Catastrophic exsanguination is the second leading cause of death during traumatic injury; thus, the resuscitative goal of MT includes rapid hemostasis and maintenance of adequate tissue oxygenation to prevent end organ damage. Various MT algorithms have been published and depend on a hospital's capabilities and preferences (Table 1).

\section{Non-trauma MTPs}

Refractory bleeding due to medical illness or surgical procedures often requires significant fluid replacement, including blood product transfusion, to resuscitate patients. Various clinical settings, such as gastrointestinal bleeding, intracranial bleeding, vascular surgical bleeding, and general surgical bleeding, are common indications for non-trauma MTPs when massive hemorrhage definitions are met. Many times trauma MTP algorithms are usually adopted fully or with minimal modifications in the non-trauma setting given the ease of transferring this practice. However, the optimal algorithm has not been impartially established or prospectively validated. A retrospective study showed that the use of an MTP in a non-trauma setting was associated with poor clinical outcomes, most probably related to underlying disease, not the MTP itself. ${ }^{9,10}$ However, this study and a similar retrospective study ${ }^{10}$ both observed that non-trauma MTPs were over-activated more than 50\% of the time without subsequent MT. In one of the studies examining blood product wastage, platelet wastage was significantly higher in non-trauma MTPs versus trauma MTPs (12.8\% versus $8.1 \%) .{ }^{10}$ Prospective studies are clearly needed to optimize non-trauma MTPs, including validation of different ratios and development of screening/prediction tools to determine which patients would most benefit from an MTP

\section{Current MT guidelines}

Guidelines are designed to provide evidence-based, wellbalanced information regarding the benefits and limitations of therapeutic interventions. Two major guidelines are available for MT: the European guidelines by the Task Force for Advanced Bleeding Care in Trauma (updated in 2013) and the Trauma Quality Improvement Program (TQIP) recommendations from the American College of Surgeons. ${ }^{11}$ The Task Force has included a new dedicated section discussing the implementation and adherence to evidence-based, protocolized clinical practices relating to blood transfusion in bleeding trauma patients. Notably, a significant portion of these guidelines is dedicated to a discussion of the utility of rapid and pertinent laboratory tests, evaluation of clinically significant hemorrhage, and administration of appropriate blood products for resuscitation in a timely manner. Similarly, the 2011 update on the clinical practice guidelines for blood conservation from the Society of Thoracic Surgeons and the Society of Cardiovascular Anesthesiologists also advocates the judicious use of blood products, factor concentrates, hemostatic agents, and blood salvage to minimize blood loss. ${ }^{12}$ In addition, the American College of Surgeons has established the TQIP to provide recommendations for the care provided to trauma patients. It also provides guidelines for MTPs, which emphasize tight collaboration among blood banks, emergency departments, anesthesiologists, and trauma services. TQIP recommends that an MTP needs to define protocol triggers for activation/ deactivation, an algorithm for preparation and delivery of blood products, including continued support in the nonemergency department (ED) setting. The guidelines advocate the establishment of transfusion targets, recommend the use of pharmacologic hemostatic agents, and suggest ongoing evaluation of cumulative MTP performance. A recent survey by TQIP evaluated over 180 registered trauma centers on their current MTP practices (Table 2). ${ }^{13}$ 
Table I Published patient-cohort specific massive transfusion protocols

\begin{tabular}{|c|c|c|c|c|}
\hline Source (year) & Package I & Package 2 & Package 3 & Note \\
\hline \multicolumn{5}{|l|}{ Adult MTP } \\
\hline O'Keeffe et a ${ }^{85}$ (2008) & 5 RBCs, 2 AB TP & 5 RBCs, 2 TP, I SDP & $\begin{array}{l}5 \text { RBCs, } 2 \text { TP, IOU } \\
\text { cryo, FVIla }\end{array}$ & \\
\hline Cotton et al ${ }^{86}$ (2009) & I0 RBCs, 4 AB TP, 2 SDP & 6 RBCs, 4 AB TP, 2 SDP & Repeat package 2 & Cryo with physician request \\
\hline Dente et $\mathrm{a}^{87}$ (2009) & 6 RBCs, 4 AB TP & $6 \mathrm{RBCs}, 6 \mathrm{TP}, \mathrm{I} \mathrm{SDP}$ & 6 RBCs, 6 TP, IOU cryo & rFVIla at clinician discretion \\
\hline Riskin et al ${ }^{88}$ (2009) & 6 RBCs, 4 FFP, I SDP & Repeat package I & Repeat package I & Consider rFVIla after 2 rounds \\
\hline Nunez et al ${ }^{89}(2010)$ & I0 RBCs, 6 AB TP, 2 SDP & Repeat package I & Repeat package I & \\
\hline Tan et a $9^{90}(2012)$ & 4 RBC, 4 AB FFP & 4 RBC, 4 AB FFP & 4 RBC, 4 AB FFP, 2 SDP & $\begin{array}{l}\mathrm{rFVIla} \text { is considered for } \\
\text { refractory bleeding and is at } \\
\text { trauma team's discretion }\end{array}$ \\
\hline Ball et al ${ }^{91}(2013)$ & 6 RBCs, 6 plasma & 6 RBCs, 6 plasma, I SDP & $\begin{array}{l}6 \text { RBCs, } 6 \text { plasma, } \\
20 U \text { cryo }\end{array}$ & $\begin{array}{l}\text { Consider rFVIla after } 2 \text { rounds } \\
\text { (abdominal surgery) }\end{array}$ \\
\hline Bawazeer et al92 (2015) & 6 RBCs, 4 AB FFP, I SDP & 4 RBCs, 4 FFP & Repeat package 2 & $\begin{array}{l}\text { IOU cryo when fibrinogen } \\
<\mathrm{I.5} \mathrm{g} / \mathrm{L} \text {, and rFVIlla is at } \\
\text { physician's discretion }\end{array}$ \\
\hline Maciel et $\mathrm{a}^{93}(20 \mid 5)$ & 6 RBCs, 4 FFP, I SDP & $\begin{array}{l}\text { RBC:FFP }(I: I) \text { plus cryo } \\
\text { and SDP }\end{array}$ & Repeat package 2 & $\begin{array}{l}\text { rVlla and TXA are at } \\
\text { physician's discretion } \\
\text { (abdominal aoritic injury) }\end{array}$ \\
\hline \multicolumn{5}{|c|}{ Pediatric/adolescent MTP } \\
\hline Riskin et al ${ }^{88}$ (2009) & 4 RBCs, 2 FFP, I SDP & Repeat package I & Repeat package I & Consider rFVIla after 2 rounds \\
\hline \multirow[t]{4}{*}{ Dressler et $\mathrm{a}^{194}(2010)$} & I RBC, I plasma, I RDP & Repeat package I & Repeat package I & $\begin{array}{l}<3 \mathrm{~kg}, \mathrm{rFVlla} \text { and cryo are } \\
\text { at physician's discretion }\end{array}$ \\
\hline & 2 RBC, 2 plasma, 2 RDP & Repeat package I & Repeat package I & $\begin{array}{l}3-20 \mathrm{~kg}, \mathrm{rFVlla} \text { and cryo are } \\
\text { at physician's discretion }\end{array}$ \\
\hline & 4 RBC, 4 plasma, 4 RDP & Repeat package I & Repeat package I & $\begin{array}{l}2 \mathrm{I}-40 \mathrm{~kg}, \mathrm{rFVlla} \text { and cryo } \\
\text { are at physician's discretion }\end{array}$ \\
\hline & 6 RBC, 6 plasma, 6 RDP & Repeat package I & Repeat package I & $\begin{array}{l}>40 \mathrm{~kg}, \mathrm{rFVlla} \text { and cryo are } \\
\text { at physician's discretion }\end{array}$ \\
\hline Pickett and Tripi ${ }^{95}(20 \mathrm{II})$ & 6 RBC, 3 FFP, 5 RDP & 5 RBC, 3 FFP, 5 RDP & $\begin{array}{l}5 \text { RBC, } 2 \text { FFP, } 5 \text { RDP, } \\
\text { I0U cryo }\end{array}$ & \\
\hline Chidester et al ${ }^{96}(2012)$ & I RBC, I FFP, I RDP & Repeat package I & Repeat package I & $\begin{array}{l}\text { rFVlla is at physician's } \\
\text { discretion }\end{array}$ \\
\hline \multirow[t]{5}{*}{ Hendrickson et al ${ }^{97}(2012)$} & I/2 RBC, I/2 plasma & $\begin{array}{l}\text { I/2 RBC, I/2 plasma, I/2 } \\
\text { SDP }\end{array}$ & $\begin{array}{l}\text { I/2 RBC, I/2 plasma, I } \\
\text { U cryo }\end{array}$ & $\begin{array}{l}\text { Neonate }(\mathrm{I}-5 \mathrm{~kg}), \text { I dose of } \\
\text { rFVIla at physician's discretion }\end{array}$ \\
\hline & I RBC, I plasma & I RBC, I plasma, I/2 SDP & I RBC, I plasma, $2 U$ cryo & $\begin{array}{l}\text { Infant }(6-10 \mathrm{~kg}), \text { I dose of } \\
\text { rFVIla at physician's discretion }\end{array}$ \\
\hline & 2 RBC, 2 plasma & 2 RBC, 2 plasma, I SDP & 2 RBC, 2 plasma, $4 U$ cryo & $\begin{array}{l}\text { Younger child ( } \mathrm{I} \mathrm{I}-25 \mathrm{~kg}) \text {, } \\
\text { I dose of rFVIlla at physician's } \\
\text { discretion }\end{array}$ \\
\hline & 3 RBC, 3 plasma & 3 RBC, 3 plasma, I SDP & 3 RBC, 3 plasma, 6U & $\begin{array}{l}\text { Cryo older child }(26-50 \mathrm{~kg}) \text {, } \\
\text { I dose of rFVIla at physician's } \\
\text { discretion }\end{array}$ \\
\hline & 5 RBC, 5 plasma & 5 RBC, 5 plasma, I SDP & $\begin{array}{l}5 \text { RBC, } 5 \text { plasma, } 8 \mathrm{U} \text { cryo } \\
\text { adolescent }\end{array}$ & $\begin{array}{l}>50 \mathrm{~kg} \text {, I dose of rFVlla at } \\
\text { physician's discretion }\end{array}$ \\
\hline \multicolumn{5}{|l|}{ Obstetric MTP } \\
\hline Gutierrez et al ${ }^{98}(2012)$ & $\begin{array}{l}6 \text { RBCs, } 4 \text { AB TP or LP, I } \\
\text { SDP }\end{array}$ & Repeat package I & Repeat package I & $\begin{array}{l}\text { Consider rFVlla as salvage } \\
\text { treatment }\end{array}$ \\
\hline
\end{tabular}

Note: IU cryo =I individual unit (not 5- or 10-pooled unit) of cryoprecipitate.

Abbreviations: RBCs, red blood cells; RDP, random donor platelets; SDP, single donor apheresis platelets; FFP, fresh frozen plasma; TP, thawed plasma; LP, liquid plasma; TXA, tranexamic acid; rFVIla, recombinant-activated factor VII.

\section{Selection of available blood products \\ Red blood cells}

To minimize blood product wastage, most blood banks aim to transfuse the oldest units first. However, the clinical impact of the RBC storage lesion has been heavily discussed and debated recently. ${ }^{14}$ The clinical effect of storage lesions and transfusing older RBCs has been insightfully described by Wang et al in a meta-analysis article evaluating over 20 published studies, which suggested that transfusing older blood is significantly associated with an increased mortality risk. However, the significance of this association appears 
Table 2 Summary of 2013 American College of Surgeons Trauma Quality Improvement Program (ACS-TQIP) Survey

\begin{tabular}{|c|c|}
\hline Surveyed categories & $\begin{array}{l}\text { Major findings (\% of surveyed } \\
\text { ACS-TQIP trauma centers) }\end{array}$ \\
\hline Prehospital resuscitation & $\begin{array}{l}\text { The most common blood products used } \\
\text { were RBCs (28\%) and plasma (10\%) } \\
\text { The most common intravenous } \\
\text { hemostatic agent used is TXA (15\%) }\end{array}$ \\
\hline MTP activation triggers & $\begin{array}{l}\text { The most common trigger used was } \\
\text { hypotension }(56 \%) \text {, defined as SBP } \\
\text { of } \leq 100 \mathrm{mmHg}(86 \%) \\
\text { Laboratory values were used } \\
\text { infrequently ( } 26 \%) \text { to initiate MTP }\end{array}$ \\
\hline $\begin{array}{l}\text { Blood product use } \\
\text { and policies }\end{array}$ & $\begin{array}{l}\text { Plasma is available immediately or in } \\
<5 \text { minutes }(64 \%-72 \%) \text {. The most common } \\
\text { plasma type used was thawed plasma or } \\
\text { plasma frozen within } 24 \text { hours ( } 78 \%) \\
\text { The most common plasma:RBC ratio } \\
\text { in the first cooler was } \geq 1: 2(88 \%) \\
\text { The platelet:RBC ratio of } \geq 1: 2 \text { in the } \\
\text { first blood pack was targeted ( } 79 \%) \\
\text { The use of cryoprecipitate was } \\
\text { integrated in the MTP policies ( } 49 \%)\end{array}$ \\
\hline $\begin{array}{l}\text { Hemostatic agent } \\
\text { (at hospital) }\end{array}$ & $\begin{array}{l}\text { The most common intravenous hemostatic } \\
\text { agent used was TXA (50\%) }\end{array}$ \\
\hline $\begin{array}{l}\text { Point of care } \\
\text { coagulopathy evaluation }\end{array}$ & $\begin{array}{l}\text { The integration of TEG in the MTP policies } \\
\text { was low (I8\%) }\end{array}$ \\
\hline
\end{tabular}

Abbreviations: RBCs, red blood cells; TEG, thrombelastography; MTP, massive transfusion protocol; TXA, tranexamic acid; SBP, systolic blood pressure.

to vary with different patient populations. ${ }^{15} \mathrm{McDaniel}$ et al found that the age of RBCs transfused during non-trauma MTPs was not significantly different from during trauma MTPs. However, the age of transfused RBCs increased significantly when the patient was switched to type-specific RBCs, which inevitably happens during MTPs. ${ }^{16}$ This is commonly practiced in many hospitals in order to preserve the Group $\mathrm{O}$ RhesusD (RhD) negative RBC inventory. In addition, the age of uncrossmatched Group O RBCs reserved for MTPs will vary due to hospital-specific RBC product management, thus further studies are needed in this area. Prospective randomized controlled trials (RCTs), including the ARIPI, ABLE, and RECESS trials, have shown that fresher RBCs do not significantly improve clinical outcomes or mortality in various clinical settings. ${ }^{17-19}$ However, no prospective clinical trial has been published on the effect of RBC storage age on outcomes for MT patients.

Immune-mediated hemolysis is another clinical concern during the MTP. Due to the emergent need for blood products, routine pre-transfusion testing is bypassed and uncrossmatched Group $\mathrm{O}$ RhD negative RBCs are often given. This removal of safety assurances received from the antibody screen and product cross-matching leaves alloimmunized patients at increased risk for acute or delayed hemolysis. ${ }^{20}$
In addition, residual plasma within Group O RBC units can accumulate when large quantities of Group $\mathrm{O}$ RBC units are transfused. This may theoretically lead to hemolysis due to $\mathrm{ABO}$ incompatibility based on retrospective evidence garnered from transfusing out-of-group platelets with minor ABO group incompatibility. ${ }^{21,22}$ Thus, for A, B, or AB patients, it is safest to repeat the blood type, with particular consideration of the reverse type, before resuming transfusion of RBCs of the patient's own blood group.

\section{Plasma}

Circulating coagulation factors have variable half-lives and are homeostatically maintained. During massive hemorrhage, the acute nature of significant blood volume loss could lead to uncompensated coagulopathy. Therefore, early transfusion of plasma-containing physiologic coagulation factors intuitively should reverse this condition. Until recently, universal Group AB plasma has been the standard product used during MT when the patient's blood group is initially unknown. Since Group AB donors comprise only approximately $4 \%$ of all eligible US blood donors, and the availability of Group AB plasma donors has been further reduced by the transfusionrelated acute lung injury (TRALI) mitigation strategies, Group $\mathrm{AB}$ plasma and platelet products remain scarce resources. To resolve this dilemma, the use of Group A plasma with low titer anti-B agglutinin has been considered as a practical alternative to Group AB plasma. Group A US donors are approximately ten times more abundant than $\mathrm{AB}$ donors. ${ }^{23}$ Zielinski et al evaluated the clinical impact of using universal untitered Group A plasma transfusion and found that approximately $14 \%$ of study subjects received incompatible plasma but no significant adverse events occurred. Notably, this practice reduced the use of $\mathrm{AB}$ plasma by more than $95 \% .{ }^{24}$ Another retrospective study by Chhibber et al examined the outcomes associated with the use of Group A plasma versus Group AB plasma in an emergency setting. Of the 23 patients with blood Group B or AB, no hemolytic or other adverse reactions were detected. ${ }^{25}$ Thus, transfusing low-titer $\mathrm{A}$ or even untested Group A plasma is a practical approach in MT practice. ${ }^{26}$ On the contrary, neither low-titer Group A or untitered Group A plasma is considered equivalent to Group $\mathrm{AB}$ plasma during routine plasma transfusion practice.

There are multiple plasma products available in the blood bank (Table 3). The selection of the product is determined by timeliness of product availability and the coagulation factor content. Thawing large amounts of frozen plasma during an MTP presents a formidable logistical challenge to deliver the plasma products within 5-10 minutes of the 
Table 3 Emergency plasma products available for massive transfusion

\begin{tabular}{|c|c|c|c|c|c|}
\hline Plasma type & Clinical use (country) & Thawing time & Donor exposure & Universal use? & $\begin{array}{l}\text { Product expiration } \\
\text { USA (hours) }\end{array}$ \\
\hline $\begin{array}{l}\text { Fresh frozen plasma } \\
\text { (thawed) }\end{array}$ & Worldwide & $30-45$ minutes & 1 & No & 24 at $1^{\circ} \mathrm{C}-6^{\circ} \mathrm{C}$ \\
\hline Thawed plasma & USA & No modification & 1 & No & 120 at $1{ }^{\circ} \mathrm{C}-6^{\circ} \mathrm{C}$ \\
\hline Liquid plasma & USA & No modification & I & No & 624 at $1^{\circ} \mathrm{C}-6^{\circ} \mathrm{C}$ \\
\hline \multicolumn{6}{|l|}{ Lyophilized plasma } \\
\hline LyoPlas $\mathrm{N}^{\circledR}$ & Germany & Bedside reconstitution & 1 & No & Immediate use \\
\hline INTERCEPT Lyoplasma ${ }^{\circledR}$ & France & Bedside reconstitution & 11 & Yes & Immediate use \\
\hline \multicolumn{6}{|l|}{ Pathogen-inactivated plasma } \\
\hline Amotosalen (Intercept $\left.{ }^{\circledR}\right)$ & Multiple & $30-45$ minutes & I & No & 24 at $1^{\circ} \mathrm{C}-6^{\circ} \mathrm{C}$ \\
\hline \multirow[t]{2}{*}{ Solvent detergent (Octaplas ${ }^{\circledR}$ ) } & Multiple & $30-45$ minutes & $1,000-1,500$ & No & 24 at $\mathrm{I}^{\circ} \mathrm{C}-6^{\circ} \mathrm{C}$ \\
\hline & & & & & 8 at $20^{\circ} \mathrm{C}-25^{\circ} \mathrm{C}$ \\
\hline
\end{tabular}

request. In the US after fresh frozen plasma or plasma frozen within 24 hours is thawed and stored for 24 hours, it can be relabeled as thawed plasma (TP) with up to five more days of shelf life. Therefore, TP has gained wide acceptance for MTP use. An observational study evaluating the implementation of TP in an emergency transfusion protocol demonstrated a significant reduction for plasma delivery time, overall blood transfusion volume, and 24-hour and 30-day mortality. ${ }^{27} \mathrm{TP}$ has relatively less factor V and factor VIII than fresh frozen plasma and plasma frozen within 24 hours. Liquid plasma (LP) is plasma recovered within 5 days of expiration from a WB product (never frozen); therefore, it has a shelf life of 26 days from the day of collection. In vitro studies have shown that LP, when stored at $1{ }^{\circ} \mathrm{C}-6^{\circ} \mathrm{C}$ for up to 26 days, appears to provide similar hemostatic properties to TP as assessed by thrombelastography (TEG) and inhibition of vascular endothelial cell permeability by the endothelial monolayer assay. ${ }^{28}$ Goodnough et al reported that Group AB LP may be an acceptable alternative plasma product for trauma patients with unknown blood groups. ${ }^{29}$ In comparison to traditional plasma products, lyophilized plasma is logistically more convenient to use during an emergency situation. In Germany, LyoPlas $\mathrm{N}$ is a single donor-derived product that can be stored at room temperature up to 15 months and is transfusion-related acute lung injury mitigation strategy compliant. While the single donor source reduces the risk of infection compared to pooled products, the product requires blood type-specific transfusion. A counterpart in France is branded INTERCEPT Lyoplasma. In contrast, this is a pooled, leukoreduced, pathogen-inactivated plasma product pooled from up to eleven donors. Lyoplasma can be stored at room temperature for up to 2 years and can be administered without $\mathrm{ABO}$ restriction. While these products are not yet clinically available worldwide, they are currently being evaluated in clinical trials.

\section{Platelets}

After collection from blood donors, platelets are typically stored between $20^{\circ} \mathrm{C}$ and $24^{\circ} \mathrm{C}$ with constant agitation for up to 5 days. In vitro and animal model-based studies have shown that refrigerated platelets have a shortened half-life in circulation..$^{30,31}$ While refrigeration $\left(1^{\circ} \mathrm{C}-6^{\circ} \mathrm{C}\right)$ is associated with decreased platelet viability and post-infusion increments, cold platelets have been shown to more readily aggregate in vitro and to have a better metabolic profile. ${ }^{32,33}$ During emergency resuscitation, the clinical emphasis often weighs more in favor of achieving rapid hemostasis rather than a durable increase in platelet count. Therefore, it has been suggested that refrigerated platelets dedicated for emergency transfusion may have clinical benefits.

\section{Whole blood}

In MT, blood component therapy attempts to recapitulate the qualities of WB; thus, the direct use of WB for bleeding trauma patients in a civilian setting has gained increasing attention. A platelet-sparing leukoreduction filter (ImuFlex, Terumo BCT, Lakewood, CO) system was recently approved by the FDA for WB processing. A single institution RCT evaluated the 24-hour transfusion volume in trauma patients receiving either $\mathrm{WB}$ or blood component therapy. While WB transfusion did not significantly reduce the transfusion volume in all patients, a portion of the trauma patients transfused with WB did receive significantly less blood volume. ${ }^{34}$ There are ongoing clinical trials to examine the effects of WB transfusion in emergency settings. The major hurdle preventing the widespread use of platelet-sparing WB products is the lack of consensus on the optimal storage condition. An in vitro functional analysis on stored pathogen-inactivated WB treated with riboflavin and ultraviolet light revealed that a colder storage temperature $\left(4^{\circ} \mathrm{C}\right)$ significantly preserved the hemostatic properties and 
platelet function..$^{35}$ Another major limitation to the use of WB is the requirement for type-specific blood, as the patient blood type is frequently unknown during the early phase of resuscitation. Although WB appears to be a promising practice during MT, more practice optimization is needed prior to its wide acceptance.

\section{Hemostatic therapies}

The use of lyophilized factor concentrates and pharmacologic agents during MT has gained popularity as they can be stored and administered at the bedside to avoid time delays due to product processing and issuing. In addition, this allows the use of target-specific treatment rather than the broad and non-specific use of plasma to attempt to correct all coagulopathies. Three factor concentrates have been used in MT: prothrombin complex concentrates (PCCs), recombinantactivated factor VII, and fibrinogen concentrate.

\section{Recombinant-activated factor VII (rFVIla) and PCCs}

Two main coagulation events determine the success of rapid and sustained clot formation: thrombin generation and fibrin formation. With rapid activation of thrombin in the presence of adequate fibrinogen and platelets, the early use of rFVIIa was associated with less blood product usage and lower mortality in military patients requiring MT. ${ }^{36-38}$ A recent meta-analysis on the use of rFVIIa, in both military and civilian populations, for the prevention and treatment of hemorrhage demonstrated favorable trends in reducing blood product usage and mortality; however, there is a concurrent trend of increased thromboembolic adverse outcomes with rFVIIa. ${ }^{39}$ Therefore, rFVIIa is not recommended for routine use during MT practices.

The use of 3- or 4-factor PCCs in a MT setting is observed due to its rapid availability and potent/rapid restoration of key vitamin K-dependent clotting factors in a concentrated, low volume dose. PCCs are not available or approved for use in a MT setting in all countries. However, the use of PCCs in dilutional coagulopathy and other clinical settings has been published to show significant hemostatic efficacy. In parallel, PCCs may carry potential enhanced risk of thrombosis in subsets of MT patients due to patients' increased circulating tissue factor and decreased plasma or endothelial anticoagulant activity. ${ }^{40}$ With the lack of safety evidence, European guidelines do not endorse the use of PCC in a MT setting. ${ }^{11}$ Collectively, these hemostatic agents are potent drugs with a risk of thrombosis; therefore, the risk-to-benefit ratio should be carefully considered in an MT setting.

\section{Fibrinogen concentrate}

Fibrinogen is a coagulation factor with a large molecular weight and a long half-life. When significant intravascular loss due to prolonged bleeding occurs, its recovery will be delayed and can rapidly become clinically significant. ${ }^{41}$ Worldwide, cryoprecipitate remains the most common blood product used to replace fibrinogen and contains approximately $200-250 \mathrm{mg}$ of fibrinogen per unit. In addition to the time delay from thawing the cryoprecipitate, the thawed product expires within 6 hours in most countries. This leads to delayed availability and increased product wastage. Furthermore, cryoprecipitate is a pooled product, but not pathogen inactivated. While fibrinogen concentrate was originally developed and approved to treat congenital afibrinogenemia, many in vitro and animal models have shown that fibrinogen concentrate can strengthen clot firmness and achieve early hemostasis in the presence of thrombocytopenia and dilutional coagulopathy. ${ }^{42,43}$ A retrospective study correlating the fibrinogen level with mortality in critically injured patients revealed that fibrinogen levels less than $180 \mathrm{mg} \mathrm{dL}^{-1}$ were significantly associated with higher in-hospital death. ${ }^{44}$ Fibrinogen replacement has been shown to hasten clinical hemostasis in various bleeding patient populations, including cardiovascular surgery, postpartum hemorrhage, and orthopedic surgery. ${ }^{45-47}$ European guidelines recommend the initiation of fibrinogen replacement by fibrinogen concentrate when the plasma fibrinogen level falls below $1.5 \mathrm{~g} \mathrm{~L}^{-1}$. $^{11}$ Holcomb et al have shown that fibrinogen replacement via cryoprecipitate is often delayed and overlooked during an MTP; ${ }^{48}$ therefore, the use of fibrinogen concentrate may be well justified in an emergency setting to augment clot firmness and achieve better hemostasis. The cost of fibrinogen concentrate is much greater than cryoprecipitate in some countries.

\section{Tranexamic acid}

Antifibrinolytics, such as aminocaproic acid or tranexamic acid (TXA), inhibit the formation of plasmin; plasmin breaks down the fibrin-based clot. Therefore, they are used to improve the durability and firmness of the clot in order to enhance clinical hemostasis. Antifibrinolytic agents have been shown to be clinically beneficial in achieving hemostasis and reducing MT in exsanguinating trauma patients, especially after enhanced fibrinolytic activity has been detected. ${ }^{49}$ Several published meta-analyses have demonstrated the efficacy and safety of TXA for bleeding patients in various surgical settings. ${ }^{50-55}$ The largest prospective RCT utilizing antifibrinolytics is the Clinical Randomization of an Antifibrinolytic in Significant Hemor- 
rhage 2 (CRASH-2) trial, a multicenter study that evaluated more than 10,000 trauma patients. The data analyses revealed that timely administration of TXA (within 3 hours of injury) was associated with a modest but highly significant reduction in both overall and bleeding-related mortalities, but not in MOF or head injury. In addition, there was no significant difference between the TXA and placebo groups in blood transfusion requirements or length of hospital stay. ${ }^{56,57}$ As the effect of TXA on isolated traumatic brain injury was not well characterized in the CRASH-2 study, the CRASH-3 trial is now underway to determined optimal use of TXA in this patient population. ${ }^{58}$ The first prospective RCT on the effectiveness of high-dose TXA (4 g loading dose with $1 \mathrm{~g}$ $\mathrm{h}^{-1}$ over 6 hours) in women with postpartum hemorrhage was conducted in France. In the 144 subjects evaluated, TXA significantly reduced blood loss and transfusions. ${ }^{59}$ Currently, the World Maternal Antifibrinolytic Trial was established to examine the effect of TXA in women with postpartum hemorrhage on mortality and other adverse events. ${ }^{60}$

\section{Evaluation of coagulopathy during MTP activation Viscoelastic testing}

Currently, central laboratory-based hemostatic evaluations (eg, prothrombin time [PT], international normalized ratio [INR], activated partial thromboplastin time, fibrinogen level/activity, and platelet count) are most commonly used in all clinical settings, including trauma. However, many of these tests are not designed for diagnosis of coagulopathy or to guide hemostatic therapy. ${ }^{61}$ In addition, they may not have adequate turn-around-time (TAT) to guide coagulation factor or platelet replacement during the fast pace of a MT. Thus, an accurate and rapid POC device to evaluate a patient's pre- and post-transfusion clotting capacity would be a great asset to direct blood transfusion and the use of hemostatic agents. Currently, there are two POC assays to evaluate real-time global coagulation function using viscoelastic methodology: thrombelastography $\left(\mathrm{TEG}^{\circledR}\right)$ and rotational thromboelastometry $\left(\right.$ ROTEM $\left.^{\circledR}\right)$. Viscoelastic testing evaluates the four main components of hemostasis: clot initiation, clotting amplification, clot firmness, and the dynamics of fibrinolysis (Figure 1). To date, there are more than 30 clinical trials showing that viscoelastic testing can reduce blood transfusion and improve clinical outcomes in patients with surgery- and trauma-related massive hemorrhage. Tapia et al have shown that MT guided by $\mathrm{TEG}^{\circledR}$ is superior in resuscitating patients with penetrating trauma when compared to standard MT practice. ${ }^{62}$ Notably, a recent prospective RCT

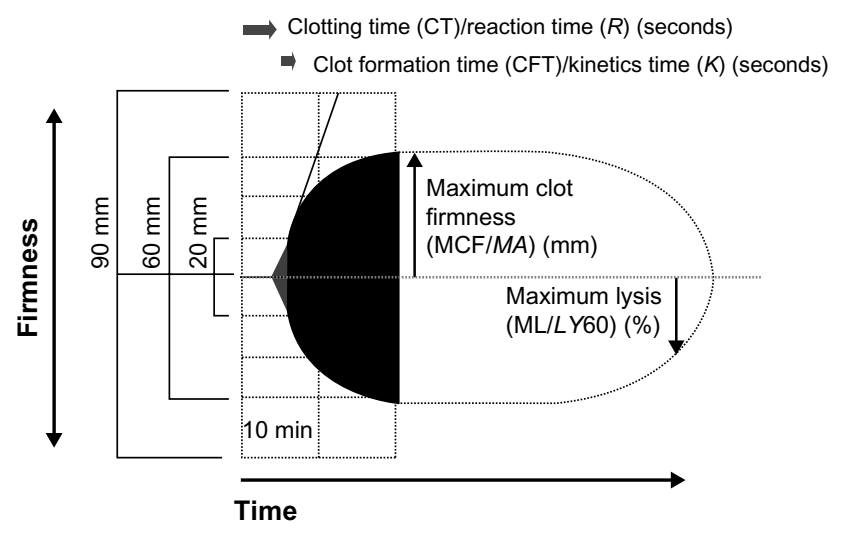

Figure I Parameters of ROTEM and TEG.

Abbreviations: MA, maximum amplitude; LY, clot lysis; TEG, thrombelastography; ROTEM, rotational thromboelastometry.

showed that FIBTEM A5 (the clot firmness in a functional fibrinogen test of ROTEM ${ }^{\circledR}$ at 5 minutes) is an independent predictor for greater than $2.5 \mathrm{~L}$ of blood loss during postpartum hemorrhage. ${ }^{46}$ Similarly, Meyer et al demonstrated that ROTEM $^{\circledR}$ clot firmness at 10 minutes was helpful in predicting who would require MT in a trauma population. ${ }^{63}$ Thus, not only can viscoelastic testing provide real-time coagulation analysis, it also has the potential to predict large blood loss and may be a useful MTP prediction tool. In addition, it has the ability to guide early, targeted therapy and allows the monitoring and early treatment of hyperfibrinolysis. Many hospitals have incorporated immediate viscoelastic testing within an hour of admission and after each MTP cooler until bleeding is controlled surgically to enhance practice during trauma MTPs. With ROTEM ${ }^{\circledR} / \mathrm{TEG}^{\circledR}$ monitoring, hemostatic therapy is guided using a combination of plasma (or PCCs in countries where they are available), platelets, fibrinogen (fibrinogen concentrate or cryoprecipitate), and antifibrinolytic agents (TXA or aminocaproic acid). This approach is most effective when transfusion algorithms incorporating POC testing have been created and practitioners have been appropriately trained on the protocols. Additional studies evaluating the utilization of viscoelastic testing in non-trauma MTPs and the ideal location for testing POC/blood bank/ central laboratory would be worthwhile.

\section{POCWB prothrombin time assay}

Laboratory-based plasma PT and INR are simple tests designed to monitor warfarin effect, but they have been widely adopted to evaluate hemostasis and assess general bleeding risk. The use of PT/INR has been integrated into several predictive algorithms for MTP activation due to its simple procedure, low cost, and transfusion predictability; ${ }^{64-66}$ however, its significant delay in TAT ( $\sim 30-60$ minutes) 
makes it less practical to direct timely therapeutic decisions during patient resuscitation with blood products. With the availability of a POC PT/INR assay using WB, the results of the PT/INR can be rapidly available at the patient's bedside during MT. Two observational studies have compared the performance of POC PT/INR assay against either plasma PT/ INR or TEG in the setting of trauma. ${ }^{67,68}$ The investigators in one study concluded that POC PT/INR assay has comparable accuracy to the laboratory-based PT/INR assay, and the ability to predict blood transfusion requirements. ${ }^{67}$ In addition, they reported a significant reduction of TAT and laboratory costs (including reagents and labor). However, performance is specific to each individual POC device and larger studies examining various commonly used POC PT/INR devices in various clinical settings and types of coagulopathy will be required to gain full endorsement for this testing option.

\section{Designing an optimal MTP Predicting MTP utilization}

As trauma patients requiring MT often die within 6 hours of medical resuscitation efforts, ${ }^{69,70}$ a reliable formula to predict MTP usage would be of great value. There are several published algorithms to predict the need for trauma-MTP

Table 4 MT prediction algorithms

\begin{tabular}{|c|c|}
\hline Algorithms & Prediction parameters \\
\hline $\begin{array}{l}\text { Trauma-associated severe } \\
\text { hemorrhage (TASH) }\end{array}$ & $\begin{array}{l}\text { Hgb, base excess, systolic BP, HR, } \\
\text { FAST }(+) \text {, male sex, pelvic and femur } \\
\text { fractures }\end{array}$ \\
\hline Prince of Wales & Hgb, systolic BP, GCS, HR, FAST (+), \\
\hline Hospital (PWH) & base deficit, pelvic fracture \\
\hline $\begin{array}{l}\text { Assessment of blood } \\
\text { consumption (ABC) }\end{array}$ & Penetrating trauma, BP, HR, FAST $(+)$ \\
\hline $\begin{array}{l}\text { Trauma-induced Coagulopathy } \\
\text { Clinical Score (TICCS) }\end{array}$ & Injury severity, BP, extent of injury \\
\hline $\begin{array}{l}\text { Automated software-derived } \\
\text { prediction (Mackenzie et } \mathrm{al}^{77} \text { ) }\end{array}$ & $\begin{array}{l}\mathrm{HR}, \mathrm{SpO}_{2} \text {, wave form analysis } \\
\text { (pulse oximeter values) }\end{array}$ \\
\hline Traumatic Bleeding Severity & Age, sex, systolic BP, FAST (+), \\
\hline Score (TBSS) & pelvic fracture, lactate \\
\hline Leemann et $\mathrm{al}^{75}$ & $\begin{array}{l}\text { ROTEM (A5, A I0, Maximum Clot } \\
\text { Firmness) }\end{array}$ \\
\hline Olaussen et $\mathrm{al}^{81}$ & Shock Index (HR, systolic BP) \\
\hline Barbosa et $\mathrm{al}^{78}$ & $\begin{array}{l}\text { GCS, pH, HR, age, Injury Severity } \\
\text { Score, 6-hour RBC transfusion } \\
\text { requirement }\end{array}$ \\
\hline Huang et $\mathrm{al}^{64}$ & Pre-operative INR \\
\hline Hsu et $\mathrm{al}^{65}$ & $\begin{array}{l}\text { INR, base deficit, hemoperitoneum at } \\
\text { laparotomy }\end{array}$ \\
\hline Callcut et al ${ }^{66}$ & $\begin{array}{l}\text { INR, systolic BP, Hgb, base deficit, } \\
\text { FAST }(+), H R \text {, penetrating trauma }\end{array}$ \\
\hline
\end{tabular}

Abbreviations: Hgb, hemoglobin; BP, blood pressure; HR, heart rate; FAST, Focused Assessment with Sonography in Trauma; GCS, Glascow Coma Scale; $\mathrm{SpO}_{2}$, peripheral blood oxygen saturation; INR, international normalized ratio. in both civilian and military settings (Table 4). ${ }^{64-66,71-78}$ For example, Assessment of Blood Consumption scoring system developed by Cotton et al is a non-weighted scoring system that was validated at multiple Level I trauma centers. It is a simple system, relying on only a few rapidly obtainable clinical parameters, yet its performance was robust. ${ }^{76,79}$ Most recently, the shock index (SI), which is the ratio of heart rate to systolic blood pressure, was developed as a simple predictor to evaluate trauma outcomes. ${ }^{80,81}$ Sohn et al have evaluated the use of SI in the setting of postpartum hemorrhage and found that SI can also independently predict the use of MTP in that setting. ${ }^{82}$ Other weighted scoring systems incorporating laboratory values, such as the Trauma-Associated Severe Hemorrhage and the Prince of Wales Hospital scores also appear to be reliable predictive tools for MTP utilization. ${ }^{83,84}$ Furthermore, POC instrument-based predictive algorithms have gained a great deal of interest due to simplicity, faster TAT, and less inter-observer variability. ${ }^{75,77}$ There are several published comparative studies to determine the ideal predictive system; however, the results vary due to different validation cohorts and study design biases. These systems have not been studied extensively in either the non-trauma MTP or pediatric MTP setting. A systematic comparison of these algorithms is needed to generate the best consensus practice to predict the need for MTP.

\section{Logistical and safety considerations}

Many MTPs begin with blood from a remote refrigerator in the emergency department or trauma bay. Often these refrigerators are stocked with Group O RBCs and occasionally TP in large trauma centers. Additional blood can be obtained from the blood bank in coolers. The amount and type of blood products per cooler varies depending on institutional preference and the blood bank inventory (see examples in Table 1). ${ }^{85-98}$ A prolonged MTP (more than 10-20 blood products) can quickly exhaust the supply of universal blood products, including Group O RBCs. Many blood banks use a rule of greater than 10 units issued before switching to $\mathrm{RhD}$ positive (for $\mathrm{RhD}$ negative patients) or antigen untested RBCs for patients with atypical red cell alloantibodies, but occasionally if sufficient $\mathrm{RBC}$ units are not available, the switch must occur earlier. During an MTP, time-consuming blood component processing, such as irradiation or cell washing, is not feasible.

Although MT can be life-saving, it carries inherent risk and harm that may occur when it is utilized inappropriately (Table 5). As blood products are needed emergently during an MTP, routine pre-transfusion testing is bypassed. Uncrossmatched Group O RhD negative RBCs, Group AB 
Table 5 Adverse complications associated with massive transfusion

\begin{tabular}{ll}
\hline Acute & Delayed \\
\hline TRALI & Hemolysis \\
TACO & TRIM \\
Citrate toxicity/hypocalcemia & Transfusion-associated GvHD \\
Hypothermia & Microchimerism \\
Allergic reaction & Transfusion-transmitted infection \\
Hyperkalemia & Posttransfusion purpura \\
Hemodilution (pediatric) & \\
Dilutional coagulopathy/ & \\
thrombocytopenia & \\
Febrile non-hemolytic transfusion & \\
reaction & \\
Electrolyte and acid-base imbalance & \\
Infection & \\
Multiorgan failure & \\
Systemic inflammatory response & \\
syndrome & \\
\hline
\end{tabular}

Abbreviations: TRALI, transfusion-related acute lung injury; TACO, transfusionassociated fluid overload; TRIM, transfusion-related immunomodulation; GvHD, graft versus host disease.

or low titer Group A plasma, and Group AB or A platelets are conventionally used. These blood products may result in various adverse transfusion events, including hemolysis, alloimmunization, hypothermia, citrate toxicity, and hyperkalemia. The switch from Group $\mathrm{O} \mathrm{RhD}$ negative $\mathrm{RBCs}$ to the patient's specific blood type should occur as soon as possible after the patient's blood type has been confirmed on two independent specimens.

\section{Timely MTP activation and deactivation}

MT is a resource-intensive process. As exsanguinationassociated death usually happens during the first few hours of admission, this resuscitative effort needs to occur within minutes. For many trauma centers, the time to issue the first MTP cooler is usually within 5-10 minutes from protocol activation. Given the need for rapid TAT and large amounts of different blood products, the blood bank often requires a dedicated team to coordinate blood preparation for the duration of MTP activation. Predictably, the rapid mobilization of large amounts of blood products in response to highly unpredictable clinical needs often results in inefficient use and blood product wastage. To ensure that an MTP is legitimately activated and to reduce potential unnecessary blood transfusion, transfusion medicine specialists are often consulted prior to commencing with MTP blood preparation, especially for non-trauma cases. In parallel, the clinical physicians should be educated on the appropriate use of MTPs. At the bedside, the clinician who activates the MTP should serve as the liaison to inform the blood bank about the need for continuing transfusion support or deactivation of the MTP. Timely deactivation of MTPs not only reduces wastage, but also may prevent unnecessary adverse events associated with MTP. A formal retrospective process involving the blood bank and the clinical teams to evaluate the efficiency and performance of each MTP and the associated outcomes can be beneficial to continuously improve the MTP.

\section{Appropriate product ratios during MT}

Without the universal availability of POC testing, an optimized transfusion strategy with appropriate blood component selection is critical. Several published retrospective studies have shown that a higher plasma to $\mathrm{RBC}$ ratio in MT is associated with better survival in patients with traumatic injuries. ${ }^{99}$ Since 2007, there has been a rather accelerated shift in MT practice to utilize a higher plasma:platelet:RBC ratio. ${ }^{100,101}$ However, the retrospective studies are thought to be flawed due to survival bias (patients who survive longer are more likely to receive plasma). Holcomb et al conducted a prospective observational study on the effect of a higher plasma:RBC ratio on in-hospital mortality. Over 900 eligible trauma patients receiving more than three

Table 6 Summary of findings from PROMMTT and PROPPR studies

\begin{tabular}{|c|c|c|}
\hline & PROMMTT $^{102}$ & PROPPR $^{103}$ \\
\hline Year & 2013 & 2015 \\
\hline Source & JAMA surgery & JAMA \\
\hline Study design & Prospective observational & Randomized control trial \\
\hline Intervention & Plasma:RBCs (I:I) & Plasma:platelets:RBCs (I:I:I); n=338 \\
\hline Control & Plasma:RBCs (I:2) & Plasma:platelets:RBCs ( $1: 1: 2) ; n=342$ \\
\hline Cohort size (n) & 905 & 680 \\
\hline Generalizability & Multicenter study & Multicenter study \\
\hline Follow-up & 24-hour and 30-day & 24-hour and 30-day \\
\hline Primary endpoint & In-hospital mortality & 24-hour and 30-day mortality \\
\hline Outcomes & $\begin{array}{l}\text { Higher plasma:RBC ratio decreases } 6 \text {-hour mortality } \\
\text { in patients who received }>3 \text { blood products; however, } \\
\text { no association found after } 24 \text { hours of survival }\end{array}$ & $\begin{array}{l}\text { No significant difference in } 24 \text {-hour and } 30 \text {-day mortality } \\
\text { or complications. I:I:I group achieved earlier hemostasis } \\
\text { and had less mortality due to exsanguinations in } 24 \text { hours }\end{array}$ \\
\hline
\end{tabular}

Abbreviations: PROMMTT, Prospective Observational Multicenter Major Trauma Transfusion; PROPPR, Pragmatic, Randomized Optimal Platelet and Plasma Ratios. 
RBCs unit were analyzed and found that less than 1 plasma for every 2 RBC products is associated with a three- to four-fold higher death risk within 6 hours of admission. ${ }^{102}$ However, the transfused plasma:RBC ratio significantly varied within the analyzed cohort. To control for this potentially clinically significant variable, the Pragmatic, Randomized Optimal Platelet and Plasma Ratios study was conducted to examine the effect of 1:1:1 versus 1:1:2 plasma:platelet:RBC ratio on 24-hour and 30-day all-cause mortality. ${ }^{103}$ The study showed that while there was no difference in the examined all-cause mortality, there was earlier hemostasis, lower transfusion requirements, and less death due to exsanguination at 24 hours in the 1:1:1 ratio group (Table 6). While there are still study limitations and biases due to the complex nature of conducting a multicenter RCT in a trauma setting, the Pragmatic, Randomized Optimal Platelet and Plasma Ratios study concluded that the higher plasma:platelet:RBC ratio appeared to be effective in reducing mortality. A higher fibrinogen-to-RBC ratio is also associated with improved survival during MT. ${ }^{104}$ More controlled investigations are still required to establish optimal blood product ratios.

\section{Summary}

In conclusion, the best practice for MT includes an established institutional definition of MT, an accurate method for predicting which patients will require MT so therapy can be promptly initiated and over-utilization can be avoided, and finally, an established MT protocol with a clear plan for activation and use of appropriate blood products to maintain hemostasis. ${ }^{105}$ This can be achieved either by goal-directed therapy with POC testing or, when point-of-care testing is not available, fixed ratios of blood products approximating a ratio of $1: 1: 1$, with early initiation of fibrinogen replacement. Adherence to the established protocol is critical to extract the full clinical benefit of an MTP for treating either trauma or non-trauma patients.

\section{Disclosure}

TH has received speaker fees and travel support from CSL Behring GmbH, Octapharma AG, TEM International, Fresenius Kabi, and B Braun AG. MMC has received travel support from TEM International. YMSH reports no conflicts of interest in this work.

\section{References}

1. Pohlman TH, Walsh M, Aversa J, Hutchison EM, Olsen KP, Lawrence Reed R. Damage control resuscitation. Blood Rev. 2015;29(4): 251-262.

2. Cotton BA, Dossett LA, Au BK, Nunez TC, Robertson AM, Young PP. Room for (performance) improvement: provider-related factors associated with poor outcomes in massive transfusion. J Trauma. 2009; 67(5):1004-1012.
3. Diab YA, Wong EC, Luban NL. Massive transfusion in children and neonates. Br J Haematol. 2013;161(1):15-26.

4. Neff LP, Cannon JW, Morrison JJ, Edwards MJ, Spinella PC, Borgman MA. Clearly defining pediatric massive transfusion: cutting through the fog and friction with combat data. J Trauma Acute Care Surg. 2015;78(1):22-28; discussion 28-29.

5. Maegele M, Spinella PC, Schochl H. The acute coagulopathy of trauma: mechanisms and tools for risk stratification. Shock. 2012;38(5): 450-458.

6. Maegele M, Schochl H, Cohen MJ. An update on the coagulopathy of trauma. Shock. 2014;41(Suppl 1):21-25.

7. Sauaia A, Moore FA, Moore EE, Haenel JB, Read RA, Lezotte DC. Early predictors of postinjury multiple organ failure. Arch Surg. 1994; 129(1):39-45.

8. Moore FA, Moore EE, Sauaia A. Blood transfusion. An independent risk factor for postinjury multiple organ failure. Arch Surg. 1997; 132(6):620-624; discussion 624-625.

9. Morse BC, Dente CJ, Hodgman EI, et al. Outcomes after massive transfusion in nontrauma patients in the era of damage control resuscitation. Am Surg. 2012;78(6):679-684.

10. McDaniel LM, Neal MD, Sperry JL, et al. Use of a massive transfusion protocol in nontrauma patients: activate away. J Am Coll Surg. 2013; 216(6):1103-1109.

11. Spahn DR, Bouillon B, Cerny V, et al. Management of bleeding and coagulopathy following major trauma: an updated European guideline. Crit Care. 2013;17(2):R76.

12. Society of Thoracic Surgeons Blood Conservation Guideline; Task F, Ferraris VA, Brown JR, et al. 2011 update to the Society of Thoracic Surgeons and the Society of Cardiovascular Anesthesiologists blood conservation clinical practice guidelines. Ann Thorac Surg. 2011;91(3): 944-982.

13. Camazine MN, Hemmila MR, Leonard JC, et al. Massive transfusion policies at trauma centers participating in the American College of Surgeons Trauma Quality Improvement Program. J Trauma Acute Care Surg. 2015;78(6 Suppl 1):S48-S53.

14. Zimring JC. Fresh versus old blood: are there differences and do they matter? Hematology Am Soc Hematol Educ Program. 2013;2013:651-655.

15. Wang D, Sun J, Solomon SB, Klein HG, Natanson C. Transfusion of older stored blood and risk of death: a meta-analysis. Transfusion. 2012;52(6):1184-1195.

16. McDaniel LM, Triulzi DJ, Cramer J, et al. Massive transfusion protocol activation does not result in preferential use of older red blood cells. J Blood Transfus. 2014;2014:328967.

17. Fergusson DA, Hebert P, Hogan DL, et al. Effect of fresh red blood cell transfusions on clinical outcomes in premature, very low-birth-weight infants: the ARIPI randomized trial. J Am Med Assoc. 2012;308(14): 1443-1451.

18. Steiner ME, Ness PM, Assmann SF, et al. Effects of red-cell storage duration on patients undergoing cardiac surgery. N Engl J Med. 2015; 372(15):1419-1429.

19. Lacroix J, Hebert PC, Fergusson DA, et al. Age of transfused blood in critically ill adults. $N$ Engl J Med. 2015;372(15):1410-1418.

20. Dutton RP, Shih D, Edelman BB, Hess J, Scalea TM. Safety of uncrossmatched type-O red cells for resuscitation from hemorrhagic shock. J Trauma. 2005;59(6):1445-1449.

21. McManigal S, Sims KL. Intravascular hemolysis secondary to ABO incompatible platelet products. An underrecognized transfusion reaction. Am J Clin Pathol. 1999;111(2):202-206.

22. Fung MK, Downes KA, Shulman IA. Transfusion of platelets containing ABO-incompatible plasma: a survey of 3156 North American laboratories. Arch Pathol Lab Med. 2007;131(6):909-916.

23. Reid ME, Lomas-Francis C, Olsson ML. The Blood Group Antigen Factsbook. 4th ed. Amsterdam: Elsevier/AP; 2012.

24. Zielinski MD, Johnson PM, Jenkins D, Goussous N, Stubbs JR. Emergency use of prethawed Group A plasma in trauma patients. J Trauma Acute Care Surg. 2013;74(1):69-74; discussion 74-65. 
25. Chhibber V, Greene M, Vauthrin M, Bailey J, Weinstein R. Is group A thawed plasma suitable as the first option for emergency release transfusion? (CME). Transfusion. 2014;54(7):1751-1755; quiz 1750.

26. Mehr CR, Gupta R, von Recklinghausen FM, Szczepiorkowski ZM, Dunbar NM. Balancing risk and benefit: maintenance of a thawed Group A plasma inventory for trauma patients requiring massive transfusion. J Trauma Acute Care Surg. 2013;74(6):1425-1431.

27. Radwan ZA, Bai Y, Matijevic N, et al. An emergency department thawed plasma protocol for severely injured patients. JAMA Surg. 2013; 148(2):170-175.

28. Cao Y, Dua A, Matijevic N, et al. Never-frozen liquid plasma blocks endothelial permeability as effectively as thawed fresh frozen plasma. J Trauma Acute Care Surg. 2014;77(1):28-33; discussion 33.

29. Goodnough LT, Spain DA, Maggio P. Logistics of transfusion support for patients with massive hemorrhage. Curr Opin Anaesthesiol. 2013; 26(2):208-214.

30. Murphy S, Gardner FH. Effect of storage temperature on maintenance of platelet viability - deleterious effect of refrigerated storage. $N$ Engl J Med. 1969;280(20):1094-1098.

31. Jansen AJ, Josefsson EC, Rumjantseva V, et al. Desialylation accelerates platelet clearance after refrigeration and initiates GPIbalpha metalloproteinase-mediated cleavage in mice. Blood. 2012;119(5): 1263-1273.

32. Montgomery RK, Reddoch KM, Evani SJ, CapAP, RamasubramanianAK. Enhanced shear-induced platelet aggregation due to low-temperature storage. Transfusion. 2013;53(7):1520-1530.

33. Reddoch KM, Pidcoke HF, Montgomery RK, et al. Hemostatic function of apheresis platelets stored at 4 degrees $\mathrm{C}$ and 22 degrees C. Shock. 2014;(41 Suppl 1):54-61.

34. Cotton BA, Podbielski J, Camp E, et al. A randomized controlled pilot trial of modified whole blood versus component therapy in severely injured patients requiring large volume transfusions. Ann Surg. 2013;258(4):527-532; discussion 532-523.

35. Pidcoke HF, McFaul SJ, Ramasubramanian AK, et al. Primary hemostatic capacity of whole blood: a comprehensive analysis of pathogen reduction and refrigeration effects over time. Transfusion. 2013;53(Suppl 1):S137-S149.

36. Perkins JG, Schreiber MA, Wade CE, Holcomb JB. Early versus late recombinant factor VIIa in combat trauma patients requiring massive transfusion. J Trauma. 2007;62(5):1095-1099; discussion 1099-1101.

37. Spinella PC, Perkins JG, McLaughlin DF, et al. The effect of recombinant activated factor VII on mortality in combat-related casualties with severe trauma and massive transfusion. J Trauma. 2008;64(2):286-293 discussion 293-284.

38. Dempfle CE, Borggrefe M. Acidosis and impaired blood coagulation: what and how to correct before using recombinant human factor VIIa. Crit Care Med. 2007;35(6):1627-1629.

39. Lin Y, Stanworth S, Birchall J, Doree C, Hyde C. Recombinant factor VIIa for the prevention and treatment of bleeding in patients without haemophilia. Cochrane Database Syst Rev. 2011;(2):CD005011.

40. Tanaka KA, Mazzeffi M, Durila M. Role of prothrombin complex concentrate in perioperative coagulation therapy. J Intensive Care. 2014;2(1):60.

41. Hayakawa M, Gando S, Ono Y, Wada T, Yanagida Y, Sawamura A. Fibrinogen level deteriorates before other routine coagulation parameters and massive transfusion in the early phase of severe trauma: a retrospective observational study. Semin Thromb Hemost 2015;41(1):35-42.

42. Velik-Salchner C, Haas T, Innerhofer P, et al. The effect of fibrinogen concentrate on thrombocytopenia. J Thromb Haemost. 2007;5(5): 1019-1025.

43. Hagisawa K, Nishikawa K, Yanagawa R, et al. Treatment with fibrinogen gamma-chain peptide-coated, adenosine $5^{\prime}$-diphosphate-encapsulated liposomes as an infusible hemostatic agent against active liver bleeding in rabbits with acute thrombocytopenia. Transfusion. 2015;55(2): 314-325.
44. Inaba $\mathrm{K}$, Karamanos $\mathrm{E}$, Lustenberger $\mathrm{T}$, et al. Impact of fibrinogen levels on outcomes after acute injury in patients requiring a massive transfusion. J Am Coll Surg. 2013;216(2):290-297.

45. Rahe-Meyer N, Solomon C, Hanke A, et al. Effects of fibrinogen concentrate as first-line therapy during major aortic replacement surgery: a randomized, placebo-controlled trial. Anesthesiology. 2013; 118(1):40-50.

46. Collins PW, Lilley G, Bruynseels D, et al. Fibrin-based clot formation as an early and rapid biomarker for progression of postpartum hemorrhage: a prospective study. Blood. 2014;124(11):1727-1736.

47. Mittermayr M, Streif W, Haas T, et al. Hemostatic changes after crystalloid or colloid fluid administration during major orthopedic surgery: the role of fibrinogen administration. Anesth Analg. 2007; 105(4):905-917, table of contents.

48. Holcomb JB, Fox EE, Zhang X, et al. Cryoprecipitate use in the Prospective Observational Multicenter Major Trauma Transfusion study (PROMMTT). J Trauma Acute Care Surg. 2013;75(1 Suppl 1): S31-S39.

49. Chapman MP, Moore EE, Ramos CR, et al. Fibrinolysis greater than $3 \%$ is the critical value for initiation of antifibrinolytic therapy. J Trauma Acute Care Surg. 2013;75(6):961-967; discussion 967.

50. Ker K, Prieto-Merino D, Roberts I. Systematic review, meta-analysis and meta-regression of the effect of tranexamic acid on surgical blood loss. Br J Surg. 2013;100(10):1271-1279.

51. Baharoglu MI, Germans MR, Rinkel GJ, et al. Antifibrinolytic therapy for aneurysmal subarachnoid haemorrhage. Cochrane Database Syst Rev. 2013;8:CD001245.

52. Pundir V, Pundir J, Georgalas C, Fokkens WJ. Role of tranexamic acid in endoscopic sinus surgery - a systematic review and meta-analysis. Rhinology. 2013;51(4):291-297.

53. Breau RH, Kokolo MB, Punjani N, et al. The effects of lysine analogs during pelvic surgery: a systematic review and meta-analysis. Transfus Med Rev. 2014;28(3):145-155.

54. Alshryda S, Sukeik M, Sarda P, Blenkinsopp J, Haddad FS, Mason JM. A systematic review and meta-analysis of the topical administration of tranexamic acid in total hip and knee replacement. Bone Joint $J$. 2014;96-B(8):1005-1015.

55. Cheriyan T, Maier SP 2nd, Bianco K, et al. Efficacy of tranexamic acid on surgical bleeding in spine surgery: a meta-analysis. Spine $J$. 2015;15(4):752-761.

56. CRASH-2 Trial Collaborators, Shakur H, Roberts I, et al. Effects of tranexamic acid on death, vascular occlusive events, and blood transfusion in trauma patients with significant haemorrhage (CRASH-2): a randomised, placebo-controlled trial. Lancet. 2010;376(9734):23-32.

57. CRASH-2 Collaborators, Roberts I, Shakur H, et al. The importance of early treatment with tranexamic acid in bleeding trauma patients: an exploratory analysis of the CRASH-2 randomised controlled trial. Lancet. 2011;377(9771):1096-1101, 1101. e1091-1092.

58. Dewan Y, Komolafe EO, Mejia-Mantilla JH, et al. CRASH-3 tranexamic acid for the treatment of significant traumatic brain injury: study protocol for an international randomized, double-blind, placebocontrolled trial. Trials. 2012;13:87.

59. Ducloy-Bouthors AS, Jude B, Duhamel A, et al. High-dose tranexamic acid reduces blood loss in postpartum haemorrhage. Crit Care 2011;15(2):R117.

60. Shakur H, Elbourne D, Gulmezoglu M, et al. The WOMAN Trial (World Maternal Antifibrinolytic Trial): tranexamic acid for the treatment of postpartum haemorrhage: an international randomised, double blind placebo controlled trial. Trials. 2010;11:40.

61. Haas T, Fries D, Tanaka KA, Asmis L, Curry NS, Schochl H. Usefulness of standard plasma coagulation tests in the management of perioperative coagulopathic bleeding: is there any evidence? $\mathrm{Br} \mathrm{J}$ Anaesth. 2015;114(2):217-224.

62. Tapia NM, Chang A, Norman M, et al. TEG-guided resuscitation is superior to standardized MTP resuscitation in massively transfused penetrating trauma patients. J Trauma Acute Care Surg. 2013;74(2): 378-385; discussion 385-376. 
63. Meyer AS, Meyer MA, Sorensen AM, et al. Thrombelastography and rotational thromboelastometry early amplitudes in 182 trauma patients with clinical suspicion of severe injury. J Trauma Acute Care Surg. 2014;76(3):682-690.

64. Huang CJ, Cheng KW, Chen CL, et al. Predictive factors for pediatric patients requiring massive blood transfusion during living donor liver transplantation. Ann Transplant. 2013;18:443-447.

65. Hsu JM, Hitos K, Fletcher JP. Identifying the bleeding trauma patient: predictive factors for massive transfusion in an Australasian trauma population. J Trauma Acute Care Surg. 2013;75(3):359-364.

66. Callcut RA, Cotton BA, Muskat P, et al. Defining when to initiate massive transfusion: a validation study of individual massive transfusion triggers in PROMMTT patients. J Trauma Acute Care Surg. 2013;74(1):59-65, 67-58; discussion 66-57.

67. David JS, Levrat A, Inaba K, et al. Utility of a point-of-care device for rapid determination of prothrombin time in trauma patients: a preliminary study. J Trauma Acute Care Surg. 2012;72(3):703-707.

68. Goodman MD, Makley AT, Hanseman DJ, Pritts TA, Robinson BR. All the bang without the bucks: defining essential point-of-care testing for traumatic coagulopathy. J Trauma Acute Care Surg. 2015;79(1):117-124.

69. Solagberu BA, Adekanye AO, Ofoegbu CP, Udoffa US, AbdurRahman LO, Taiwo JO. Epidemiology of trauma deaths. West Afr J Med. 2003; 22(2):177-181.

70. Demetriades D, Murray J, Charalambides K, et al. Trauma fatalities: time and location of hospital deaths. J Am Coll Surg. 2004;198(1):20-26.

71. Maegele M, Lefering R, Wafaisade A, et al. Revalidation and update of the TASH-Score: a scoring system to predict the probability for massive transfusion as a surrogate for life-threatening haemorrhage after severe injury. Vox Sang. 2011;100(2):231-238.

72. Rainer TH, Ho AM, Yeung JH, et al. Early risk stratification of patients with major trauma requiring massive blood transfusion. Resuscitation. 2011;82(6):724-729.

73. Ogura T, Nakamura Y, Nakano M, et al. Predicting the need for massive transfusion in trauma patients: the Traumatic Bleeding Severity Score. J Trauma Acute Care Surg. 2014;76(5):1243-1250.

74. Tonglet ML, Minon JM, Seidel L, Poplavsky JL, Vergnion M. Prehospital identification of trauma patients with early acute coagulopathy and massive bleeding: results of a prospective non-interventional clinical trial evaluating the Trauma Induced Coagulopathy Clinical Score (TICCS). Crit Care. 2014;18(6):648.

75. Leemann $\mathrm{H}$, Lustenberger $\mathrm{T}$, Talving $\mathrm{P}$, et al. The role of rotation thromboelastometry in early prediction of massive transfusion. $J$ Trauma. 2010;69(6):1403-1408; discussion 1408-1409.

76. Cotton BA, Dossett LA, Haut ER, et al. Multicenter validation of a simplified score to predict massive transfusion in trauma. J Trauma. 2010;(69 Suppl 1):S33-S39.

77. Mackenzie CF, Wang Y, Hu PF, et al. Automated prediction of early blood transfusion and mortality in trauma patients. $J$ Trauma Acute Care Surg. 2014;76(6):1379-1385.

78. Barbosa RR, Rowell SE, Sambasivan CN, et al. A predictive model for mortality in massively transfused trauma patients. J Trauma. 2011;71 (2 Suppl 3):S370-S374.

79. Nunez TC, Voskresensky IV, Dossett LA, Shinall R, Dutton WD, Cotton BA. Early prediction of massive transfusion in trauma: simple as ABC (assessment of blood consumption)? J Trauma. 2009;66(2):346-352.

80. Pacagnella RC, Souza JP, Durocher J, et al. A systematic review of the relationship between blood loss and clinical signs. PLoS One. 2013;8(3):e57594.

81. Olaussen A, Peterson EL, Mitra B, O’Reilly G, Jennings PA, Fitzgerald M. Massive transfusion prediction with inclusion of the pre-hospital Shock Index. Injury. 2015;46(5):822-826.

82. Sohn CH, Kim WY, Kim SR, et al. An increase in initial shock index is associated with the requirement for massive transfusion in emergency department patients with primary postpartum hemorrhage. Shock. 2013;40(2):101-105.
83. Brockamp T, Nienaber U, Mutschler M, et al. Predicting on-going hemorrhage and transfusion requirement after severe trauma: a validation of six scoring systems and algorithms on the TraumaRegister DGU. Crit Care. 2012;16(4):R129.

84. Mitra B, Rainer TH, Cameron PA. Predicting massive blood transfusion using clinical scores post-trauma. Vox Sang. 2012;102(4):324-330.

85. O'Keeffe T, Refaai M, Tchorz K, Forestner JE, Sarode R. A massive transfusion protocol to decrease blood component use and costs. Arch Surg. 2008;143(7):686-690; discussion 690-681.

86. Cotton BA, Au BK, Nunez TC, Gunter OL, Robertson AM, Young PP. Predefined massive transfusion protocols are associated with a reduction in organ failure and postinjury complications. $J$ Trauma. 2009;66(1):41-48; discussion 48-49.

87. Dente CJ, Shaz BH, Nicholas JM, et al. Improvements in early mortality and coagulopathy are sustained better in patients with blunt trauma after institution of a massive transfusion protocol in a civilian level I trauma center. J Trauma. 2009;66(6):1616-1624.

88. Riskin DJ, Tsai TC, Riskin L, et al. Massive transfusion protocols: the role of aggressive resuscitation versus product ratio in mortality reduction. J Am Coll Surg. 2009;209(2):198-205.

89. Nunez TC, Young PP, Holcomb JB, Cotton BA. Creation, implementation, and maturation of a massive transfusion protocol for the exsanguinating trauma patient. J Trauma. 2010;68(6):1498-1505.

90. Tan JN, Burke PA, Agarwal SK, Mantilla-Rey N, Quillen K. A massive transfusion protocol incorporating a higher $\mathrm{FFP} / \mathrm{RBC}$ ratio is associated with decreased use of recombinant activated factor VII in trauma patients. Am J Clin Pathol. 2012;137(4):566-571.

91. Ball CG, Dente CJ, Shaz B, et al. The impact of a massive transfusion protocol (1:1:1) on major hepatic injuries: does it increase abdominal wall closure rates? Can J Surg. 2013;56(5):E128-E134.

92. Bawazeer M, Ahmed N, Izadi H, McFarlan A, Nathens A, Pavenski K. Compliance with a massive transfusion protocol (MTP) impacts patient outcome. Injury. 2015;46(1):21-28.

93. Maciel JD, Gifford E, Plurad D, et al. The impact of a massive transfusion protocol on outcomes among patients with abdominal aortic injuries. Ann Vasc Surg. 2015;29(4):764-769.

94. Dressler AM, Finck CM, Carroll CL, Bonanni CC, Spinella PC. Use of a massive transfusion protocol with hemostatic resuscitation for severe intraoperative bleeding in a child. J Pediatr Surg. 2010;45(7): 1530-1533.

95. Pickett PM, Tripi PA. Massive transfusion protocol in pediatric trauma. Int Anesthesiol Clin. 2011;49(2):62-67.

96. Chidester SJ, Williams N, Wang W, Groner JI. A pediatric massive transfusion protocol. J Trauma Acute Care Surg. 2012;73(5): 1273-1277.

97. Hendrickson JE, Shaz BH, Pereira G, et al. Implementation of a pediatric trauma massive transfusion protocol: one institution's experience. Transfusion. 2012;52(6):1228-1236.

98. Gutierrez MC, Goodnough LT, Druzin M, Butwick AJ. Postpartum hemorrhage treated with a massive transfusion protocol at a tertiary obstetric center: a retrospective study. Int J Obstet Anesth. 2012;21(3): 230-235.

99. Borgman MA, Spinella PC, Perkins JG, et al. The ratio of blood products transfused affects mortality in patients receiving massive transfusions at a combat support hospital. J Trauma. 2007;63(4): $805-813$.

100. Kautza BC, Cohen MJ, Cuschieri J, et al. Changes in massive transfusion over time: an early shift in the right direction? J Trauma Acute Care Surg. 2012;72(1):106-111.

101. Kutcher ME, Kornblith LZ, Narayan R, et al. A paradigm shift in trauma resuscitation: evaluation of evolving massive transfusion practices. JAMA Surg. 2013;148(9):834-840.

102. Holcomb JB, del Junco DJ, Fox EE, et al. The prospective, observational, multicenter, major trauma transfusion (PROMMTT) study: comparative effectiveness of a time-varying treatment with competing risks. JAMA Surg. 2013;148(2):127-136. 
103. Holcomb JB, Tilley BC, Baraniuk S, et al. Transfusion of plasma, platelets, and red blood cells in a 1:1:1 vs a 1:1:2 ratio and mortality in patients with severe trauma: the PROPPR randomized clinical trial. J Am Med Assoc. 2015;313(5):471-482.

104. Stinger HK, Spinella PC, Perkins JG, et al. The ratio of fibrinogen to red cells transfused affects survival in casualties receiving massive transfusions at an army combat support hospital. J Trauma. 2008; 64(2 Suppl):S79-S85; discussion S85.
105. Khan S, Allard S, Weaver A, Barber C, Davenport R, Brohi K. A major haemorrhage protocol improves the delivery of blood component therapy and reduces waste in trauma massive transfusion. Injury. 2013;44(5):587-592.

\section{Publish your work in this journal}

International Journal of Clinical Transfusion Medicine is an international, peer-reviewed, open access, online journal publishing clinicalexperimental, policy-making and evidence-based practices of all topics pertaining to clinical transfusion medicine. Original research, short reports, reviews, case reports and commentaries are invited.
The manuscript management system is completely online and includes a very quick and fair peer-review system, which is all easy to use. Visit http://www.dovepress.com/testimonials.php to read real quotes from published authors.

\footnotetext{
Submit your manuscript here: http://www.dovepress.com/international-journal-of-clinical-transfusion-medicine-journal
} 